\title{
Integrating Exploitative and Explorative Thinking in Business Process Analysis: A Conceptual Model and Method
}

\author{
Integrando os Pensamentos Analítico e Intuitivo na Análise de Processos de Negócio
}

\author{
Carina Frota Alves ${ }^{1 *}$, Hígor Ricardo Monteiro Santos²
}

\begin{abstract}
Ambidextrous BPM has gained increasing interest from researchers and practitioners in the last years. It refers to the ability to use exploitative and explorative capabilities in BPM projects. In this paper, we investigate how the integration of exploitative and explorative ideas can leverage the analysis of business processes. The key contributions of this paper are a conceptual model and a method that integrate ambidextrous thinking in a complementary way. Both artefacts were evaluated by means of an expert opinion survey. We also present a case study at an organisation that has implemented our proposed method. We believe that ambidextrous analysis of business processes enables organisations tackling current operational bottlenecks while simultaneously exploring external opportunities for designing innovation in business processes.
\end{abstract}

Keywords: Ambidextrous BPM - Exploitative and Explorative Techniques - Business Process Analysis Design Science Research

Resumo: O BPM ambidestro tem obtido um interesse crescente de pesquisadores e profissionais nos últimos anos. Ele refere-se à capacidade de usar recursos analíticos e intuitivos em projetos de BPM. Neste artigo, investigamos como a integração de idéias analíticas e intuitivas pode potencializar a análise de processos de negócio. As principais contribuições deste artigo são um modelo conceitual e um método que integra o pensamento ambidestro de maneira complementar. Ambos os artefatos foram avaliados por meio de uma pesquisa com especialistas. Também apresentamos um estudo de caso em uma organização que implementou 0 método proposto. Acreditamos que a análise ambidestra dos processos de negócio permite que as organizações enfrentem os gargalos operacionais atuais e, ao mesmo tempo, explorem oportunidades externas para projetar a inovação nos processos de negócios.

Palavras-Chave: BPM Ambidestro - Técnicas Analíticas e Intuitivas - Análise de Processo de Negócio Design Science Research

${ }^{1}$ Centro de Informática, Universidade Federal de Pernambuco, Brazil

${ }^{2}$ Universidade de Pernambuco, Brazil

*Corresponding author: cfa@cin.ufpe.br

DOI: http://dx.doi.org/10.22456/2175-2745.106891 • Received: 27/08/2020 • Accepted: 07/12/2020

CC BY-NC-ND 4.0 - This work is licensed under a Creative Commons Attribution-NonCommercial-NoDerivatives 4.0 International License.

\section{Introduction}

Business Process Management (BPM) is a maturing discipline. Over the decades, BPM has shown to be a valuable approach to increase corporate performance. Dumas et al. [1] define BPM as the body of methods, techniques, and tools to discover, analyse, redesign, execute and monitor business processes. Lately, BPM community has been increasingly focusing on the cultural, social, and innovation impact of BPM $[2,3]$.

Organisations have been challenged to adapt fast to external changes and provide real value for customers. To survive in turbulent times, organisations should be seeking disruptive innovations and new business models while still pursuing incremental gains of current processes. As a result, process analysts must simultaneously handle current bottlenecks and problems in business processes by using traditional analytical techniques (e.g., Desk Research, Ishikawa Diagram and $5 \mathrm{~W} 2 \mathrm{H}$ ) as well as explore external opportunities (e.g., empathy map, personas and brainwriting) to transform current processes and design completely new processes.

Recently, researchers have coined the term Ambidextrous BPM $[4,5]$. It is considered the dynamic balance of business process efficiency and flexibility [6]. Ambidextrous BPM refers to the ability to combine exploitative and explorative capabilities in BPM initiatives [7]. These frames of thinking 
are somehow contradictory forces that must co-exist [8].

Exploitative-oriented BPM includes efforts for reducing deviations in processes, automating manual tasks, and cutting cost. It is considered improvement-driven and follows an inside-out view. In contrast, Explorative-oriented BPM is an opportunity-driven and outside-in approach. It focuses on radical transformations in business processes that truly improve customer experience and bring new revenue streams for the organisation. The goal of exploration is assessing how technological trends such as mobile technologies or cloud computing can be adopted to innovate the organisation's business processes [9].

Our research aims to contribute to the emerging area of ambidextrous BPM. In this paper, we investigate how the combination of exploitative and explorative ideas and capabilities can leverage the analysis of business processes. Our research question is: How to analyse business processes in order to exploit organisational problems and explore innovation opportunities through the lens of ambidextrous thinking?

We adopted a Design Science Research (DSR) method to investigate this problem. During our research, we conducted two cycles of DSR and designed two artefacts: a method and a conceptual model to support the ambidextrous analysis of business processes. In this paper, we focus on the second cycle of DSR, which includes the refinement of the method and design of the conceptual model.

In addition, we validated both artefacts through an expert opinion survey and implemented the method by means of a case study at an organisation with experience in BPM. The conceptual model provides researchers with a reference foundation to define the process analysis phase taking into account the ambidextrous capabilities of the organisation. The method proposes a systematic way to conduct ambidextrous analysis of business processes. It describes a set of exploitative and explorative analysis techniques ready to be applied by practitioners.

To stimulate the creativity of process analysts, we used Design Thinking to structure the activities of our method. Design thinking is an approach to problem-solving that uses tools, practices or methods to support the development of organisations [11]. Design thinking is a way of thinking that balances both the exploitation of current knowledge and exploration of new knowledge [10].

The rest of the paper is organised as follows. Section 2 outlines the background. Section 3 presents the research method. Section 4 and 5 we present our proposed conceptual model and method for ambidextrous analysis of business process, respectively. Section 6 presents the results of the empirical studies. Finally, Section 7 presents contributions, related work, limitations and directions for future research.

\section{Background}

Ambidextrous organisations have capabilities to manage both analytical and intuitive thinking. It encompasses two different features of businesses: one that focuses on exploiting existing capabilities for incremental improvements and the other focused on exploring new opportunities for growth. As Table 1 indicates, the two features require very different strategies, structures, processes, and cultures $[11,12]$.

Table 1. Alignment for ambidextrous features by [11]

\begin{tabular}{|c|c|c|}
\hline $\begin{array}{l}\text { Alignment } \\
\text { of: }\end{array}$ & Exploitative & Explorative \\
\hline $\begin{array}{l}\text { Strategic in- } \\
\text { tention }\end{array}$ & Cost, profit & Innovation \\
\hline Critical tasks & $\begin{array}{l}\text { Operations, effi- } \\
\text { ciency, incremental } \\
\text { innovation }\end{array}$ & $\begin{array}{l}\text { Adaptability, } \\
\text { new products, } \\
\text { breakthrough } \\
\text { innovation }\end{array}$ \\
\hline Competencies & Operational & Entrepreneurial \\
\hline Structure & Formal, mechanistic & $\begin{array}{l}\text { Adaptive, } \\
\text { loose }\end{array}$ \\
\hline $\begin{array}{l}\text { Controls, re- } \\
\text { ward }\end{array}$ & Margins, productivity & $\begin{array}{l}\text { Milestones, } \\
\text { growth }\end{array}$ \\
\hline Culture & $\begin{array}{l}\text { Efficiency, low risk, } \\
\text { quality, customers }\end{array}$ & $\begin{array}{l}\text { Risk-taking, } \\
\text { speed, flexibil- } \\
\text { ity }\end{array}$ \\
\hline $\begin{array}{l}\text { Leadership } \\
\text { role }\end{array}$ & Authoritative & Visionary \\
\hline
\end{tabular}

By deploying the idea of ambidextrous organisations to the Business Process Management discipline, Rosemann [4] proposes the concepts of Exploitative BPM and Explorative BPM. Exploitative BPM is aiming towards running and incrementally improving business processes. Exploitative analysis capabilities are dedicated to assessing current processes with the aim to identify and quantify process problems. Exploitative BPM supports industries and organisations with largely static market conditions (e.g., banking back-offices, shared service providers, and mass production).

On the other hand, Rosemann [4] affirms that Explorative BPM provides a significant future opportunity, and challenge for the BPM community. Explorative BPM is about designing process visions that are so captivating and transformational that they motivate staff and customers, involved to explore how to make a desired future state. For example, the design of novel digital channels to support citizens regarding the public services provided by a local government. This is in sharp contrast to exploitative BPM, which develops new (tobe) processes to address current shortcomings. For instance, the improvement of an internal process of student registration and respective information system. The balance between exploitation and exploration, or between incremental and radical organisational change has been a consistent theme across several studies $[11,13,14]$. Grisold and colleagues highlight the importance of explorative approaches. They propose a "triple-diamond model" as a means to integrate explorative BPM activities in BPM [15].

Traditionally, business processes are analysed in a qualitative or quantitative form with the purpose to exploit, reduce or 
eliminate existing problems in the processes, such as bottlenecks, financial or resource waste, cycle time, and handworks $[16,17]$. Business process analysis is an important phase of the BPM lifecycle because it provides a critical examination of problems and potential improvements of business processes. However, few studies have been conducted to provide novel techniques and methods for the business process analysis phase [18, 19]

Business process analysis is considered an important phase of the BPM lifecycle [16, 20]. According to the International Institute of Business Analysis (IIBA), business analysis is the set of activities and techniques used to serve as a link between stakeholders in order to understand the structure, policies, and operations of an organisation and to recommend solutions that allow the organisation to achieve its goals. In addition, this phase involves understanding how organisations operate to achieve their purposes and defining the capabilities an organisation must have to provide products and services to external stakeholders [21].

In this context, the analysis of business processes should be seen as a means to propose value for the organisation [16]. In BPM initiatives, this value is transformed into improvement opportunities for the process itself, for the organisation and for its customers. As discussed in the introduction, improvement opportunities can be identified, analysed, and explored through 'inside-out' and/or 'outside-in' paradigms.

The 'inside-out' paradigm takes into account a much more reactive approach to existing problems and bottlenecks in order to enable organisational improvement [4]. On the other hand, the 'outside-in' paradigm seeks to proactively identify problems and innovation opportunities still unexplored in order to create new products, services, and business processes. Figure 1 illustrates the conflict between these two paradigms in the BPM context.

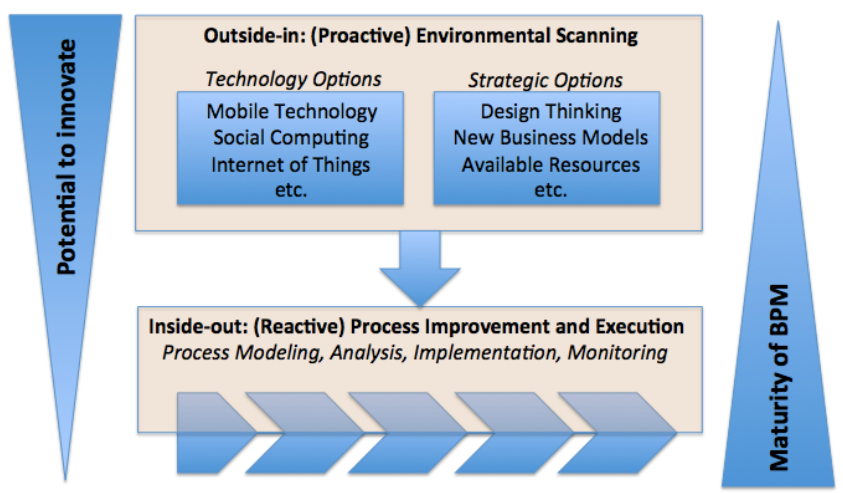

Figure 1. The Maturity-Innovation Conflict in BPM by [4])

Given this conflict, organisations need to balance their capabilities and abilities to continuously improve as well as to be attentive to market changes to innovate. Although it is difficult for organisations to balance their capabilities, Chen and Katila [14] highlight that exploration and exploitation need not always be competing activities, instead they can be complementary.
According to Brown and Wyatt [22], design thinking is an approach to support innovation and that aims to align analytical with intuitive thinking. Design thinking is a wellestablished approach that follows the 'outside-in' paradigm. Richardson et al. [23] emphasise that instead of focusing on surface adoption of new customer experience methods and techniques, design thinking forces BPM teams to think about process problems from a completely different perspective. This allows teams to be more effective in their interactions with executives, business owners, and stakeholders when focused on optimising the customer experience.

Design thinking generates an environment highly interactive and promotes innovation through the following steps: empathise, define, ideate, and prototype. Despite the high number of studies promoting the use of design thinking to create innovative products and services [24, 25, 26], few studies in the BPM area propose an integrated use of exploitative and explorative techniques to support innovation in business processes models aligned to expectations, experience and satisfaction of customers [4, 23, 27].

In the context of this research, we use concepts and practices of organisational ambidexterity and design thinking to organise and systematise the business process analysis phase. In the next section, we describe the research method used to build and evaluate the proposed method for ambidextrous of business process analysis.

\section{Research Method}

According to Wieringa [28], Design Science Research artefacts are defined as constructs (vocabulary and symbols), models (abstractions and representations), methods (algorithms and practices) and instantiations (systems or prototypes). DSR is suitable to support our study because we aim at solving a practical organisational problem by means of a designoriented research. DSR guided us through an iterative, yet structured process of building and evaluating artefacts. It provides a suitable framework to build an artefact that is useful to solve a real-world problem and is closely connected to extant knowledge in the literature [10, 29]. We adopted the DSR life cycle proposed by Wieringa [28], which contains the following steps: (1) Problem Investigation, (2) Treatment Design, (3) Treatment Validation, (4) Treatment Implementation and (5) Implementation Evaluation. We conducted two cycles of DSR.

Figure 2 presents the phases of our research. In Cycle 1 of Problem Investigation, we conducted a systematic mapping study to understand the literature in the fields of ambidextrous BPM and ambidextrous organisations. In the Treatment Design phase, we designed the A2BP Method, which is a practical artefact to guide business analysts during the activities of ambidextrous analysis of business processes. The systematic mapping study and the initial version of the method were previously published [27]. The current paper extends our previous research. Here, we proposed a conceptual model to specify ambidextrous process analysis, refined the A2BP 

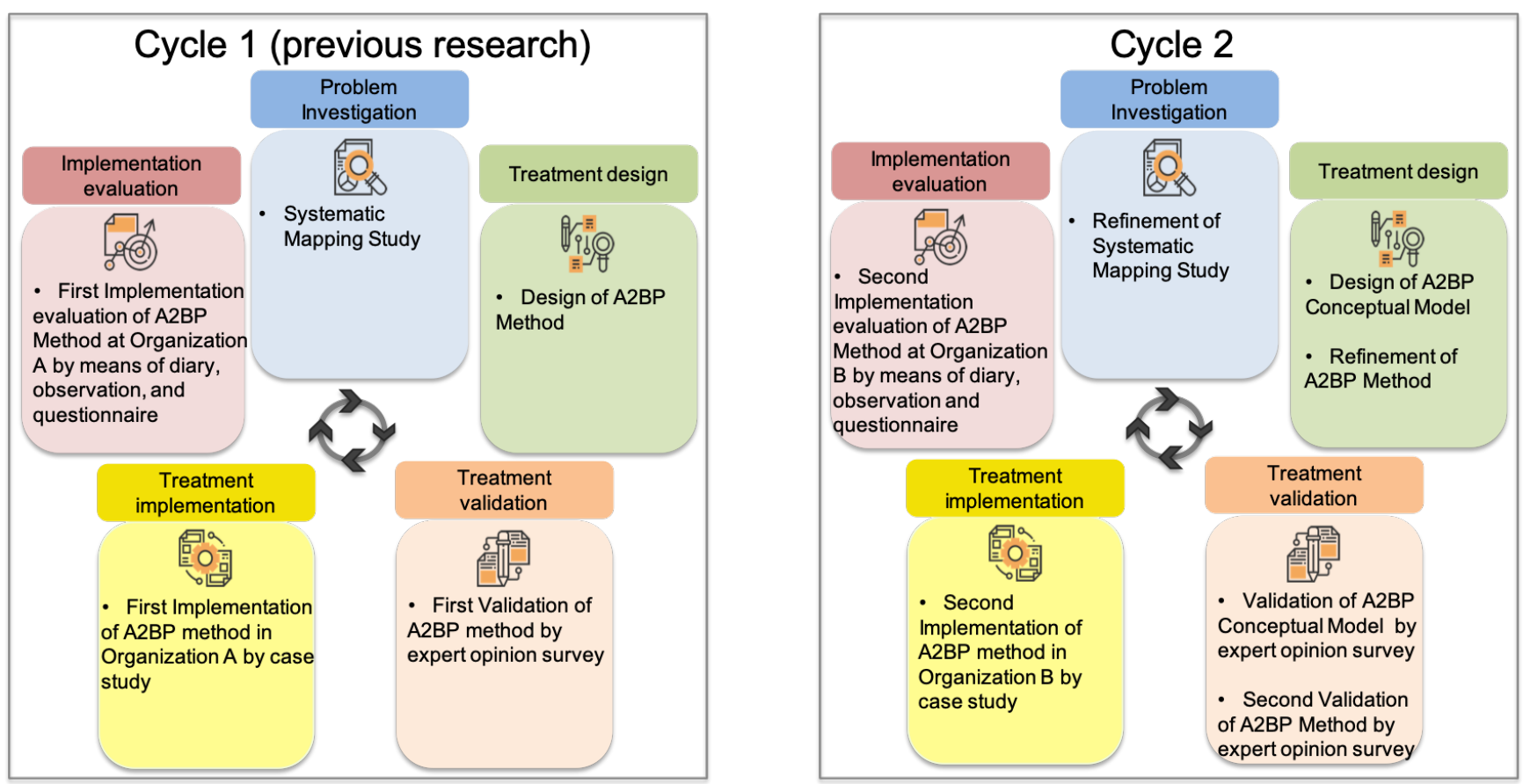

Figure 2. Design Science Research Cycles based on [28]

method and conducted new empirical studies by means of expert opinion survey and implementation of the proposed method at an organisation.

A core feature of Design Science Research is the empirical evaluation of the artefacts in the appropriate environment. According to Wieringa [28], expert opinion is a suitable and straightforward way to validate an artefact. Experts are used as instruments to observe and image a validation model of the artefact. During the Treatment Validation, we performed an expert opinion survey to initially validate and refine the method.

In the Treatment Implementation, we conducted an observational case study at organisation A to apply the method. The organisation A has the function of assisting the Legislative in the external control of the Public Administration. It performs the monitoring and auditing of public accounts. Because the method is suitable for business processes that aim to provide innovative value for customers, we chose the complaint process. This process aims to investigate information about irregularities in the administrative, financial, budgetary and balance of government agencies, including indirect administration or those who executed any public expenditure. The participants of the case study were a BPM team of the case organisation comprised of one manager and two process analysts. During the case study, one researcher participated as observer of all activities conducted by the team to apply the A2BP method. Finally, the Implementation Evaluation phase involved the critical assessment of our method. The result of this phase provided insights and opportunities to redesign our method and start a new DSR cycle.

In this paper, we present the results of the second cycle of
DSR. Cycle 2 involved the design of the A2BP Conceptual Model and the refinement of the A2BP Method during the Treatment Design phase. Both artefacts aim to support the ambidextrous analysis of business processes by integrating the exploitation of internal problems with the exploration of external opportunities to innovate. The method is a practical artefact that provides guidance for business analysts, while the conceptual model is a theoretical artefact that describes the conceptual elements involved in the ambidextrous analysis together with the relationships among them. The Treatment Validation consisted of an expert opinion survey with seventeen participants who assessed the conceptual model according to the following criteria: testability, explanatory power, parsimony and generality [29]. In addition, we also assessed the clarity of constructs and their relationships.

Experts also evaluated the refined version of the method. In the Treatment Implementation phase, we conducted an observational case study at organisation $\mathrm{B}$. We adopted the same protocol used in the first case study at organisation A, so that we maintained the consistency of our research methods. We collected case study data by means of researcher observation, participants' diary and questionnaire. Finally, in the Implementation Evaluation, we performed a critical assessment of the method.

\section{Results}

\subsection{Conceptual Model for Ambidextrous Analysis of Business Processes}

In this section, we present the conceptual model designed during the second cycle of Design Science Research. The 
proposed conceptual model is called Ambidextrous Analysis of Business Processes (A2BP) and is available at the website (https://sites.google.com/view/a2bpmodel). The conceptual model aims to structure the business process analysis through the lens of ambidexterity. The requirement for the artefact that we designed is to conduct the process analysis by simultaneously examining existing organisational problems as well as proposing innovation ideas. In general, business process analysts are not aware of the power and benefits of exploitative and explorative techniques when used together [4]. Thereby, we argue that if business processes are analysed using an ambidextrous approach, the chances are higher for analysts to identify opportunities for change, inside and outside the organisation, which will bring real value for stakeholders.

The A2BP conceptual model is suitable for researchers and practitioners to have a shared understanding concerning ambidexterity in business process analysis. Our conceptual model focuses on the definition and explanation of the concepts and relationships involved in the ambidextrous analysis of business processes. The main goals of the conceptual model are: (1) to systematise the knowledge in the domain of ambidextrous analysis; (2) to establish a common language between researchers and professionals who will perform the analysis; (3) to allow BPM teams to construct their own instantiations and specific methods based on the elements defined by the ambidextrous analysis. In addition, we proposed a practical method that operationalises the conceptual model (c.f. Section 5).

As a result of the ambidextrous analysis, BPM teams are expected to obtain novel insights aligned with the principles of ambidexterity, support the modelling of the To-Be business process or even design completely new business processes. According to O'Reilly and Tushman [30], such principles are characterised by the ability to manage complex and contradictory aspects such as efficiency and flexibility, continuous improvement and radical innovation, alignment and adaptation.

The elements of the conceptual model were obtained from a mapping study. The study included four steps: (i) automatic search in electronic databases, (ii) manual search of journals, conferences and workshops, (iii) analysis of the reference lists of other secondary studies, (iv) recommendations from colleagues who are experts in the field to identify articles that could be considered in the review. The electronic databases selected to perform the automatic search were ACM, SCOPUS, IEEE and ScienceDirect. In addition, academic papers were also searched manually in journals and conferences in the areas of Information Systems and Business Process Management, such as the Business Process Management Journal, International Conference on Business Management and Electronic Information and Journal of Innovation Management.

Table 2 presents the conceptual elements and the respective studies that cite them. The studies are: [16]; [31]; [22]; [25]; [32]; [17]; [33]; [20]; [34]; [35]; [36]; [37]; [10]; [38]; [19]. In order to select the constructs used in the proposed conceptual model, which includes the eleven elements and the six sub-elements, the construct had to be cited by at least two published studies.

Since the authors use different nomenclatures to mention similar terms, we classified the elements in macro categories to create a single taxonomy for the conceptual model. To build the conceptual model, we also used as practical knowledge the results of the empirical studies conducted in the first cycle of DSR. We observed that some studies only mention the elements but do not formally define them. Our conceptual model aims to integrate existing conceptual elements from the area of business process analysis with concepts from the area of ambidextrous thinking.

The relationship between the method, output and the analysis document is 1: 1 precisely because we take into account that each business process analysis will be done independently from another process. Therefore, a team participating in the analysis will execute an instance of the A2BP method applying 1 or more process analysis techniques. Finally, generating an output composed of a set of changes in the business process and a documentation that will assist the creation of the To-Be model. In this way, our method can be applied to different contexts. The proposed exploitation and exploration techniques are suggestions that analysts can adopt in different BPM projects.

Figure 3 presents the conceptual model. From a theoretical perspective, the model synthesise the key conceptual elements involved in the ambidextrous analysis of business processes. From a practical viewpoint, the model supports the participants of business process analysis to reflect in a systematic and balanced way on the improvement (exploitative thinking) of existing organisational problems and exploration (explorative thinking) future opportunities to innovate the business process.

In order to categorise the conceptual elements of the ambidextrous analysis, we adopted the dimensions of the basic structure of business models used to guide organisations in the development of new products or services [39]. Markides [40] suggests a simple strategy from the business area to explore the what, who and how dimensions of an organisation. In addition, we included the why dimension proposed by Turber and Smiela [41] to reflect on the reasons and benefits that will be generated.

The What dimension refers to what the analysis phase will investigate in order to propose improvements and/or innovations for the process. The Who dimension represents the actors involved in the analysis. The How dimension guides the way the business process analysis can be executed. Finally, the Why dimension highlights the benefits and gains that can be generated by the ambidextrous analysis of the process.

\subsection{Elements of What Dimension}

The What dimension involves the aspects of the business process that will be analysed in order to propose improvements and/or innovations. The elements of this dimension are: Input, 
Table 2. Conceptual elements found in literature

\begin{tabular}{ll}
\hline Conceptual Elements & Evidence \\
\hline As-Is Business Process Model & {$[16],[31],[17],[33],[20],[34],[36],[37],[38],[19]$} \\
Analysis Participant & {$[16],[32],[17],[33],[34],[37],[38]$} \\
Value Proposition & {$[16],[31],[32],[17],[33],[20],[34],[35],[36],[37],[10],[19]$} \\
Business Process Analysis Technique & {$[16],[31],[22],[25],[17],[20],[34],[37],[10],[19]$} \\
Input & {$[16],[31],[17],[33],[20],[34],[35],[36],[37],[10],[19]$} \\
Output & {$[16],[31],[17],[33],[20],[34],[35],[36],[37],[10],[19]$} \\
Analysis Plan & {$[16],[31],[22],[17],[34],[36]$} \\
As-Is Business Process Model Documentation & {$[16],[17],[33],[20],[35],[36]$} \\
Analysis Documentation to create To-Be Business & {$[16],[17],[33],[36],[10],[19]$} \\
Process Model & {$[16],[22],[25],[17],[33],[20],[35],[36],[37],[10],[19]$} \\
Business Process Change & {$[16],[31],[17],[33],[20],[34],[36],[37],[38],[19]$} \\
As-Is Business Process Model & {$[16],[32],[17],[33],[34],[37],[19]$} \\
Analysis Participant &
\end{tabular}

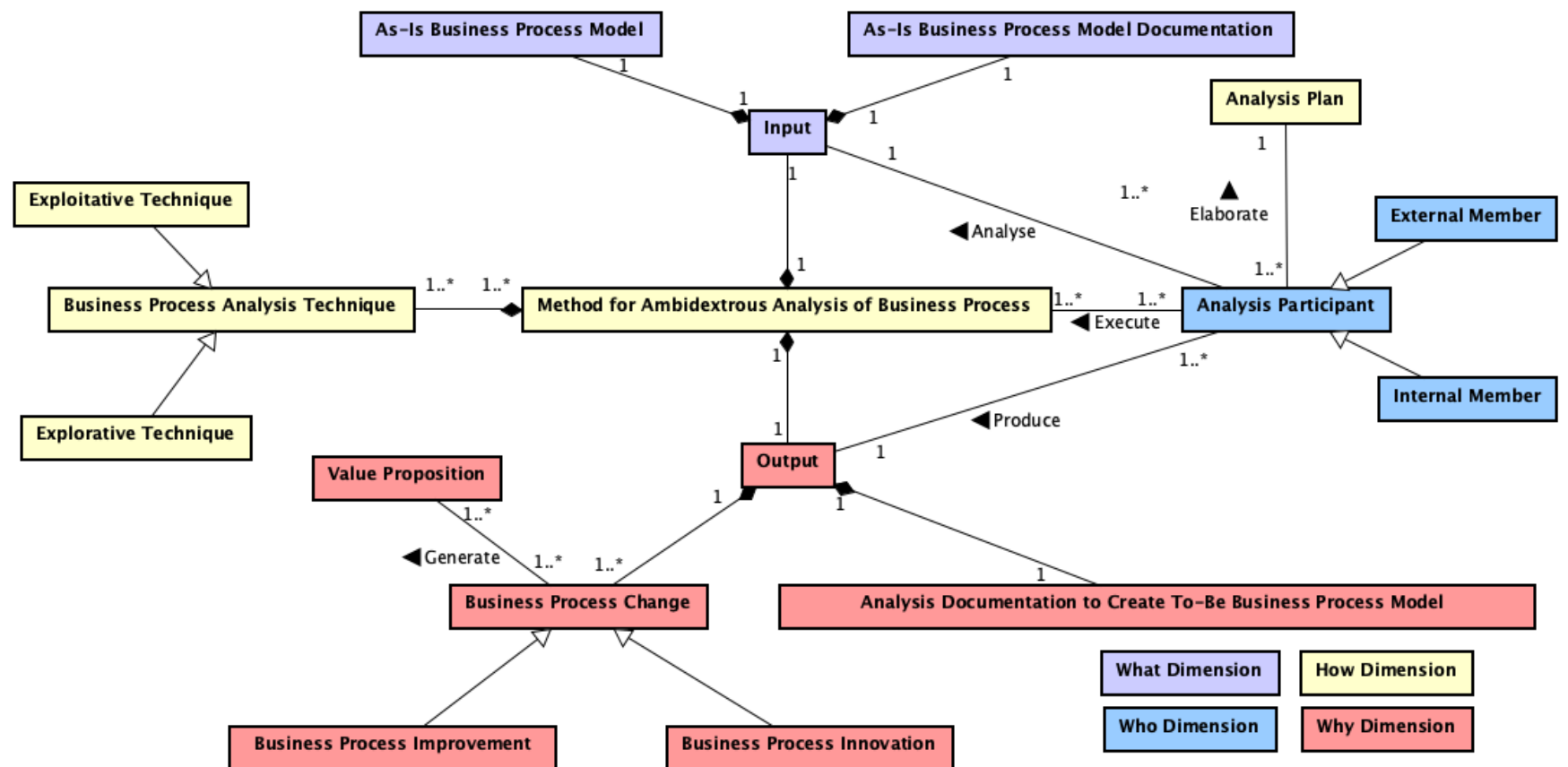

Figure 3. Conceptual Model for Ambidextrous Analysis of Business Processes)

As-Is Business Process Model and As-Is Business Process Model Documentation. The definitions of the elements are:

- Input - represents the aspects influencing the ambidextrous analysis of the business process, such as: activities, execution time, stakeholders involved, customers receiving the product and/or service generated by the business process.

- As-Is Business Process Model - is a graphical representation of the current state of the business process and the respective resources involved, such as actors, information, facilities, IT systems, financial resources. The As-Is process model is represented in notations such as: BPMN, EPC, etc.

- As-Is Business Process Model Documentation - de- scribes the set of information related to the current state of the business process. It includes different information such as: organisational policies, checklists, business rules and restrictions, links to other applications, process goals, contextual aspects, current process performance indicators, motivations for process improvement, description of process activities, list of participants, and specification of their roles and responsibilities.

\subsection{Elements of Who Dimension}

The Who dimension represents the people involved in the analysis of the business process. It includes the elements Participant of the analysis, as well as the sub-elements Internal Member and External Member: 
- Analysis Participant - set of actors who will participate in the analysis of the business process, either conducting the analysis or providing information related to the process and the business context. This element is composed of members from inside and outside the organisation. Participant discusses the Input, produces the Output, elaborates the Analysis Plan and executes the Method for Ambidextrous Analysis of Business Process.

- Internal member - staff from the organisation that plays the roles of project manager, analyst, expert, or business process owner. They are responsible for the BPM project and the execution of the business process.

- External member - actors from outside the organisation, such as: customers, suppliers, regulatory and governmental agencies, and partners. Traditionally, these actors are not directly responsible for the analysis of the business process. In contrast, in ambidextrous analysis, they have an active role to co-create new business processes. In fact, several explorative techniques actively involve customers and other external stakeholders.

\subsection{Elements of How Dimension}

The How dimension guides the BPM team during the business process analysis phase. The ambidextrous analysis is centered on the customer perspective. It contains activities that use creative thinking and ensure the synergy between explorative and exploitative techniques to provide opportunities for innovation as well as incremental improvements of the business process. It has the following elements: Method for Ambidextrous Analysis of Business Process, Analysis Plan, Business Process Analysis Technique, and the sub-elements Exploitative Technique and Explorative Technique:

- Method for Ambidextrous Analysis of Business Process - we proposed a new method with a set of phases, steps, activities, and tasks that are performed by the Analysis Participant. The method is composed of Input, Business Process Analysis Technique, and Output.

- Analysis Plan - describes the preparation for the ambidextrous analysis. It is elaborated by the Analysis Participant based on the business context and the business process under improvement (What). The plan also includes participants who join the analysis team and their roles (Who); the objectives, benefits, and scope of the analysis (Why); techniques to be used in the analysis (How); and schedule of the analysis phase (When).

- Business Process Analysis Technique - approaches that assist participants in collecting and analysing business process data. These techniques are classified in exploitative and explorative.

- Exploitative technique - a set of traditional analytical techniques to analyse processes following an "inside- out" approach. These techniques aim at correcting identified problems and incrementally improving the business process. Usual problems are eliminating waste, bottlenecks, process variations, and manual labour. Examples of exploitative techniques are: Ishikawa diagram, 5W2H, and Pareto analysis.

- Explorative technique - a set of techniques that foster creative thinking of participants. The majority of explorative techniques were originally created in other fields, such as: strategic business management, marketing, design thinking and innovation, user-centred design [42]. These techniques focus on identifying novel opportunities and future visions for the business process. They follow an "outside-in" approach to understand customers' expectation, experience and satisfaction with the goal of promoting innovation in the business process. Thus, they require active participation and engagement of customers. Explorative techniques include: user journey, empathy interview, and brainstorming.

\subsection{Elements of Why Dimension}

The Why dimension highlights the benefits and value that can be created by the ambidextrous analysis. It has the elements Output, Analysis Documentation to Create To-Be Business Process Model, Value Proposition, and Business Process Change, which has the sub-elements Business Process Improvement and Business Process Innovation:

- Output - is the result of the business process analysis after performing exploitative and explorative techniques. It includes new proposals for products and/or services that meet or exceed customers' goals. The proposals can include innovative features, superior quality, radical transformation of processes, or even the design of completely new processes and respective novel products and/or services. The main output of the analysis phase is the documentation to create the To-Be Business Process Model. In cases of radical innovation, the Analysis Participants can design a brand-new process that does not have a current As-Is process. This is a typical example of organisations that reinvent themselves.

- Analysis Documentation to Create To-Be Business Process Model - is a document presenting the results of the business process analysis. It includes both incremental improvements resulting from the use of Exploitative Techniques as well as innovations originated from Explorative Techniques. The analysis document is the basis to create the improved/novel business process.

- Business Process Change - represents new aspects of the improved/novel business process. The changes allow the process to be more efficient, effective, innovative, and/or deliver additional value to customers.

- Business Process Improvement - involves incremental improvement opportunities in the business process by 
focusing on internal organisational problems. These improvements are the result of adopting Exploitative Techniques.

- Business Process Innovation - includes innovation opportunities that increase customer satisfaction, identify future directions for the business, create new revenue streams, or originate radical transformation in the business process. The innovation is obtained by adopting Explorative Techniques.

- Value proposition - is a statement that ensures the superior value (i.e. benefit) to be delivered by the improved/novel business process. It is expected that customers will be satisfied with their experience with the product and/or service generated by the improved/novel business process. The value proposition is generated by the implementation of improvement as well as innovation opportunities. These two perspectives are equally important for the ambidextrous analysis.

\section{Method for Ambidextrous Analysis of Business Processes}

The complete Method for Ambidextrous Analysis of Business Processes (A2BP) is available at the website $\langle$ http://method. a2bp.dx.am $\rangle$. Figure 4 presents an overview of the method, which is organised in phases, activities, tasks, techniques and expected results. The method consists of three phases: Planning, Executing, and Closing. For each phase, we describe a set of exploitative and explorative techniques that can be selected by analysts.

The exploitation and exploration techniques suggested in the method were gathered from mapping study and developed by academia and industry, such as IDEO, Oracle and SAP. The Stanford Design Institute is also a major developer of Design Thinking and contributes a lot to projects, knowledge and techniques. Several approaches and techniques for analysing and improving processes have been developed and have been widely used for decades, for example, Lean Management, Six Sigma, Theory of Constraints and Workflow Analysis. However, researchers and professionals have argued that these approaches, despite being quite effective in identifying existing problems, do not provide adequate techniques and practices to identify and explore opportunities beyond their organisational boundary [4, 43, 35, 23].

Accordingly, exploitative techniques have an inside-out approach in which they use internal strategies and resources to the organisation to analyse problems and opportunities in business processes. In turn, explorative techniques have the perspective of outside-in analysis where the inputs to obtain opportunities are extracted from the customer's point of view.

In the Planning Phase, the analysis team is defined. First, they understand the business environment and gather strategic information about the organisation and the business process under review. In this activity, it is important to assess the internal and external context. The internal view highlights current problems faced by the organisation while the external outlook explores innovation scenarios and technological/market trends. Then, participants establish the analysis scope and prepare the analysis plan. The following exploitative techniques are suggested for this phase: meetings with stakeholders, interviews, and desk research. We suggest the explorative techniques of brainstorming and brainwriting to establish the scope of the business process analysis.

The Executing Phase guides the team during the ambidextrous analysis of the business process. During this phase, the business process is analysed in a holistic way. Active participation of customers and users is essential to successfully conduct the analysis. This phase is structured following the steps of Design Thinking: Empathy, Define, Ideate and Prototype [22, 41]. Our method describes several techniques to create new ideas that can incrementally improve as well as foster radical innovation in business processes. The Empathy step is the moment to deeply understand the goals, pains, and expectations of customers. During the Define step, the analysis team performs the following activities: share learning, categorise learning, and structure the opportunities. To categorise learning, the team follows the following tasks: categorise the learning in themes, criteria and personas. Then, they define opportunities to change the business process. To perform these tasks, the team can apply Ishikawa Diagram (exploitative technique) as well as User Journey and Affinity Diagram (explorative techniques). In the Ideate step, participants create and refine ideas that can be implemented by the business process. In the Prototype step, the team prepares a list of improvement and/or innovation opportunities and design a "prototype" of the To-Be business process model.

Finally, the Closing Phase involves the review of the data collected, the organisation of learning, insights, ideas, and prototypes in order to generate the documentation of the business process analysis. This documentation supports the design of the improved/novel process model by using techniques that stimulate exploitative and explorative thinking. Section 5.2 illustrates how the A2BP method was implemented in the case study.

\section{Empirical Studies to Validate the Arte- facts}

This section presents the results of the empirical studies conducted during the second cycle of DSR (c.f. Section 2) to evaluate and refine the A2BP conceptual model and method. Section 6.1 shows the results of the expert opinion survey. Section 6.2 presents the case study at organisation B that implemented the method. Finally, Section 6.3 discusses the implementation evaluation.

\subsection{Treatment Validation}

As described in the previously published article, the validation of the A2BP method in DSR Cycle 1 occurred with the participation of 10 specialists selected for convenience, according 


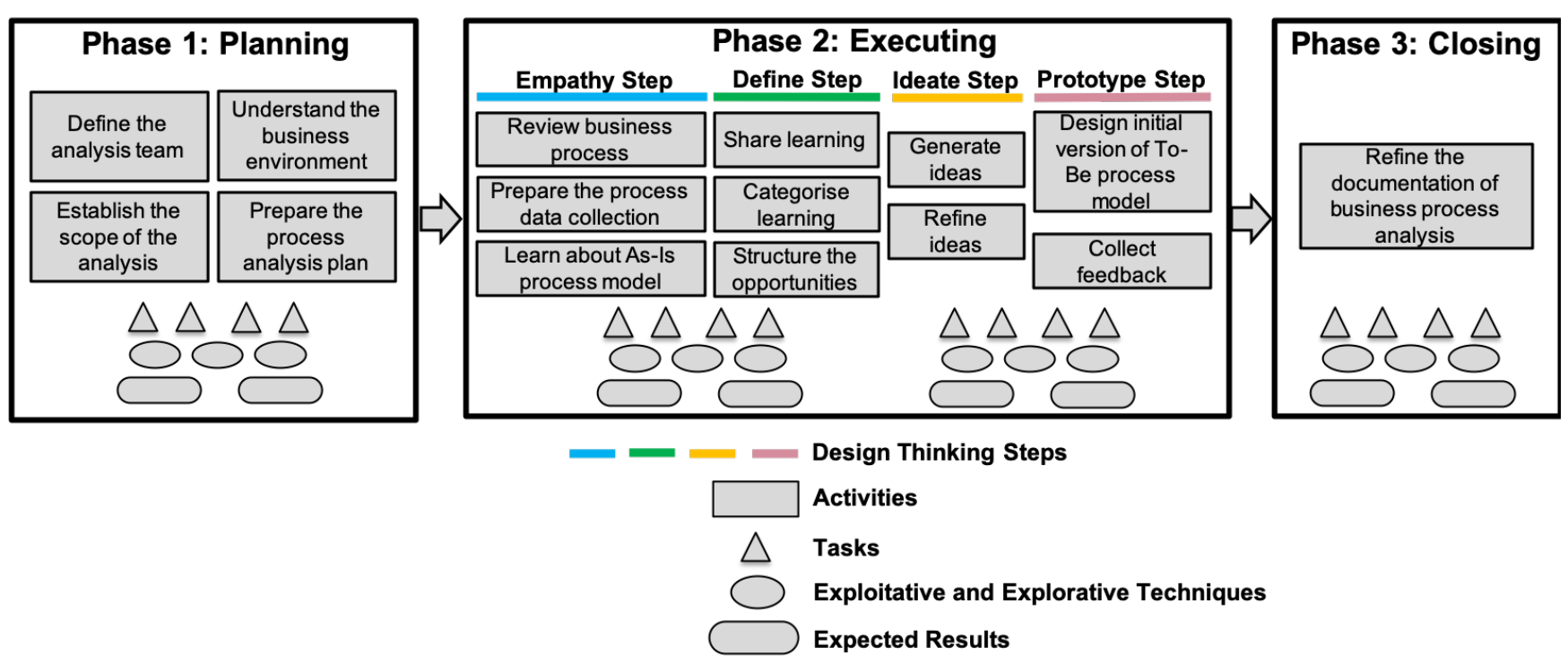

Figure 4. Overview of the A2BP Method

to their knowledge of the topic addressed and the availability to participate in the research.

In Cycle 2, we conducted the validation of the A2BP conceptual model and method by means of an expert opinion survey. We identified BPM professionals from three LinkedIn groups: BPM Professionals - Business Process Management Professionals (about 1841 participants); Business Analysts (about 13,772 members) and BPM Brasil (about 848 members). After analysing the profile of the members of these groups and verifying that they have knowledge and experience with BPM initiatives, a direct private message was sent to the participants of the LinkedIn groups. 17 specialists participated in the validation of the method and conceptual model A2BP. Nine experts have more than 8 years of experience in the field; three experts have between 6 to 8 years of experience; five experts have between 3 to 5 years of experience.

According to the instructions, experts should initially critically analyse the conceptual model, its structure, conceptual elements, relationships and then validate it through a semistructured questionnaire. Subsequently, experts had to analyse the A2BP method which includes the phases, steps, activities, tasks, techniques, expected results and then evaluate it using a semi-structured questionnaire identical to that used in Cycle 1. To validate the conceptual model ${ }^{1}$, experts rated the clarity of the dimensions and respective conceptual elements. As shown in Figure 5, the majority of experts considered the definitions of the conceptual elements and their relationships are slightly clear or extremely clear. In addition, experts provided valuable feedback to improve the definitions of the conceptual elements.

Then, we asked experts to evaluate the explanatory power, generality, parsimony, and testability of the conceptual model according to criteria proposed by [29]:

\footnotetext{
${ }^{1}$ Link to Evaluation of A2BP Conceptual Model: /http://tiny.cc/ a2bpmodel $\rangle$
}

- Explanatory power: The degree to which a theory explains and predicts all known observations within its scope;

- Generalisation: The breadth of a theory's scope and the degree to which the theory is independent of specific configurations;

- Parsimony: It is the degree to which a theory is economically constructed with a minimum of concepts and propositions;

- Testability: It is the degree to which a theory is constructed in such a way that empirical refutation is possible.

Regarding the explanatory power, eleven experts affirmed the elements are well known, three judged the elements and relations are not well known, and three experts did not know. In terms of simplicity, fourteen stated that it was simple to understand the conceptual model, two experts considered the model is not simple to be understood, one did not know. We received the following feedback regarding the explanatory power: "I think most of the elements are well known, excepting the term ambidextrous analysis". This comment suggests that ambidexterity is a competency that process analysts may not be familiar. Based on this observation, we improved the explanation of ambidextrous analysis concept. In terms of generality, fifteen participants stated that the conceptual model synthesises the key constructs involved in different types of business processes analysis, two experts disagreed. One expert commented: "At first, yes, because the model does not specify aspects of public or private business processes, it describes rather general aspects". In relation to parsimony, thirteen experts evaluated that the conceptual model is designed with a minimum of elements and relationships, two 


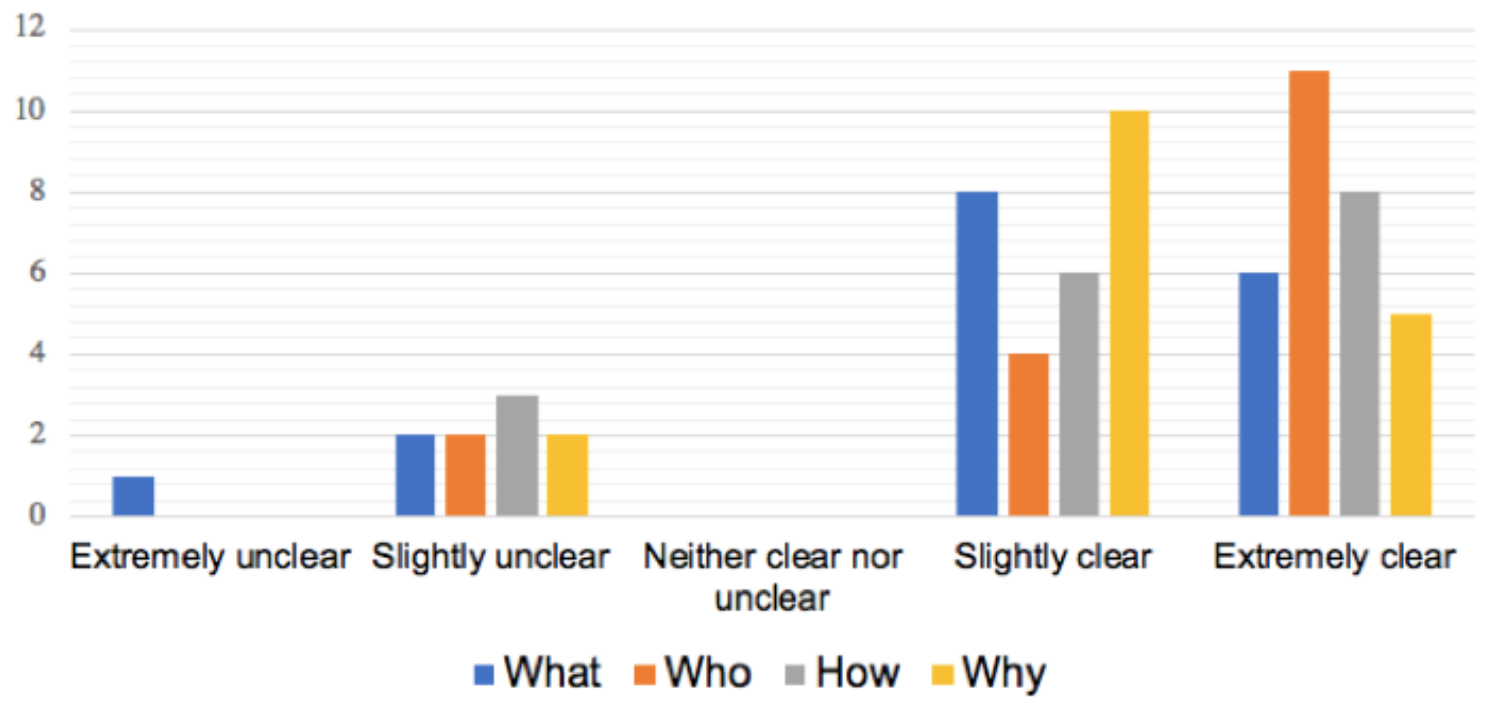

Figure 5. Clarity assessment of the conceptual elements and their relationships)

experts disagreed, and two did not know. There were no comments or suggestions on the parsimony criterion.

Finally, the testability criterion checks the internal consistency and whether the elements and their relationships can be empirically refutable. Regarding internal consistency, fourteen experts affirmed the conceptual model is consistent and it has no contradictory or ambiguous elements. Three experts considered the conceptual model is not internally consistent with its elements. However, they did not point which aspects of the model were considered inconsistent. For empirically refutable, fourteen answered positively, one expert answered no, and two experts did not know. Experts suggested the following improvements: "It would be interesting to empirically apply it in some organisations, presenting some practical examples", "I would include some Design Thinking ideas in the model". These suggestions were already taken into account in the A2BP Method since this artefact can be applied in practice by organisations and it also includes several Design Thinking principles.

In the second part of the survey ${ }^{2}$, experts evaluated the A2BP method using the evaluation criteria: understandability, perceived utility, and applicability. Ten experts fully agreed the method is easy to understand. Three experts partially agreed, three experts did not know and one partially disagreed with the assertion. Then, experts were asked if they understood how to use the exploitative and explorative techniques proposed by the method. Twelve experts said they understood how to use both types of techniques. Three partially agreed and two experts were undecided. The following suggestions to improve the understandability of method were given: "Detail explorative techniques a little more since not everyone has this knowledge"; "Some intuitive techniques seem a bit obscure"; "Build a single diagram by expanding the macro processes (of the method). It may seem larger, but it reduces

\footnotetext{
${ }^{2}$ Link to Evaluation of A2BP Method: 〈http://tiny.cc/a2bpmethod $\rangle$
}

time with navigability'.

The perceived utility refers to whether experts consider the proposed phases, activities and tasks as adequate to perform the ambidextrous analysis of business processes. Eight experts fully agreed, seven partially agreed, one did not know, and one partially disagreed. Finally, we asked experts if they think the proposed exploitative and explorative techniques are applicable to identify opportunities for improvement and innovation for business processes. Eight experts fully agreed with the assertion, four partially agreed, five did not know. In general, experts provided a positive feedback for the method but we observed they are not very familiar with the ambidextrous analysis term and they are not accustomed to use explorative techniques in their work. Experts reinforced the need to apply the method in real BPM projects to further validate it.

After analysing the answers provided by the experts, the A2BP method was refined to include their suggestions for improvement. In general, experts judged positively the ease of understanding of the phases, the flow of activities and tasks, as well as the description of the suggested techniques. As it was the first time that the A2BP method was analysed by experts, it was possible to perceive many suggestions regarding clarity of understanding. Therefore, we conducted the following improvements and refinements in the A2BP method after the review of experts:

1. The last two tasks of Activity 2 (Prepare the process data collection) have been merged and transformed into the "Plan data collection: definition of the roadmap and organisation of materials for data collection";

2. The term "process prototype" has been replaced by "initial release" and "business process views" in the Prototyping stage;

3. The executing phase contained three activities initially. As suggested by an expert, they were condensed into 
the activity "Refine business process analysis documentation";

4. In the description of the techniques, we worked on the how to apply them to ensure the techniques are simple and intuitive;

5. We included an explanation of who are the mandatory and desirable participants to apply the analytical and intuitive techniques;

6. We included a video briefly demonstrating the method and details about the research were described.

In the next section, we present a case study at an organisation that implemented the A2BP method.

\subsection{Treatment Implementation}

After the refinement of the A2BP method based on experts' feedbacks, we conducted the implementation of the method by means of an observational case study at organisation B. The study was performed between November 2017 and January 2018. Organisation B is responsible for the development and support of information systems for a Municipality. The organisation has been developing BPM projects for 9 years. Initially, we presented our research goals for the President and Chief Technology Officer of the organisation to define which BPM project we would apply the A2BP method. We agreed that the management of rotating public parking was a suitable process. The process provides a key service for citizens of this busy city and the municipality received several complains about the management of public parking.

Hence, organisation B aimed to identify opportunities to innovate the process and implement a novel platform to manage the rotating public parking. Three analysts of organisation $B$ participated in the case study. They were asked to study the material of the method available at the website and conduct the analysis of the rotating public parking process using our method to guide them. One author observed the meetings but he did not interfere in the directions of the study. We highlighted that there was no specific training on A2BP method or Design Thinking and its techniques. We tried to make the method as clear as possible for participants could perform it autonomously.

As illustrated in Figure 4, the A2BP method starts with the Planning Phase. The analysis team established the scope and goals of the project. The goals were: (1) eliminate the parking paper bead, (2) improve the supervision of rotating parking spaces, (3) provide a map of parking spaces, (4) develop a mobile app for users to purchase parking tickets online.

The outcome of this phase was the definition of the Analysis Plan. In the Execution Phase, the first step is Empathy. The analysis team assessed similar solutions proposed by other municipalities, explored alternatives available in the market, and talked to specialists in mobile technologies. Besides that, the team selected 18 users (i.e. drivers who use the public parking) who fit into the desired profiles of key users. Participants learned about the As-Is process and shared their experiences and challenges during the use of the city's public parking.

The following step is Define. This step involves the activities of share learning, categorising learning, and structure change opportunities for the process. Participants discussed the data collected. All information gathered was categorised using the Affinity Diagram technique. The following categories of issues were created: parking spaces, parking attendants, inspection, ticket purchase, revenue, special user (i.e. elderly, handicapped, pregnant women), and benefits for users. The analysis team also created 6 Personas: manager of rotating public parking, inspector, regular user, special user, mobile parking attendants, fixed parking attendants. For example, Figure 6 describes a persona created for a regular user. It describes the devices that persona Mark will use the new system (i.e. Android smartphone), his desires and challenges when parking his car in the city centre.

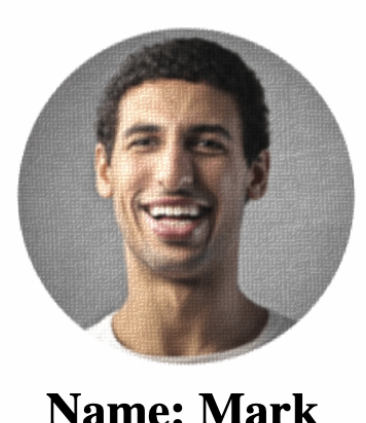

Age: 32

Job: Sales Manager in a shop Education: Bachelor in Marketing Device: Android smartphone Goals: park his car very quickly because he always arrives late for work, he wants to find a parking space near his shop because he leaves late in the evening. Challenges: $\mathrm{He}$ has difficulty finding parking spaces, he forgets to renew the paper ticket and would like to pay the parking space for the entire day.

Figure 6. Example of persona - Regular User

Then, opportunities for process change were identified, which were classified into improvement and innovation opportunities. In total, 37 opportunities were identified. Table 3 presents examples of opportunities. The understanding of users pains and expectations gathered during the Empathy step were fundamental to identify the opportunities. 
Integrating Exploitative and Explorative Thinking in Business Process Analysis

Table 3. Improvement and innovation opportunities for the rotating public parking process

\begin{tabular}{lll}
\hline Categories & Improvement Opportunity & Innovation Opportunity \\
\hline Parking spaces & $\begin{array}{l}\text { Inform location and quantity of parking space } \\
\text { or map online. }\end{array}$ & $\begin{array}{l}\text { Allow users to reserve remotely public parking } \\
\text { spaces, paying in advance for the reservation. }\end{array}$ \\
Benefits for users & $\begin{array}{l}\text { Send alerts to the user when credits are running } \\
\text { out. }\end{array}$ & $\begin{array}{l}\text { Provide access to video cameras where users } \\
\text { parked their cars. }\end{array}$ \\
Ticket purchase & $\begin{array}{l}\text { Online sales of tickets to registered or anony- } \\
\text { mous users to use public parking. }\end{array}$ & $\begin{array}{l}\text { Allow users or legal entities to transfer credit be- } \\
\text { tween them. }\end{array}$ \\
\hline
\end{tabular}

The Ideate step was carried out with the goal of generating and refining opportunities. The analysis team, two directors of organisation B and four members of the transit company participated in this step. They used the brainwriting technique to stimulate creativity to generate ideas in order to address the categories of issues defined in the previous step. The result of this step was a document with a set of insights and ideas that can be implemented by the organisation. Finally, in the Prototype step, the analysis team proposed a preliminary ToBe business process model using BPMN notation. The model described the ideas selected during the Ideate step. In addition, functional requirements were defined and low fidelity prototypes were generated describing the main functionalities for the mobile app. Figure 7 illustrates an example of prototype developed by the team.

Finally, the Closing Phase was carried out. It consisted of reviewing the documents and artefacts generated to assist in the creation of the To-Be business process model. The documentation included the opportunities for improvement and innovation proposed by the participants of the analysis. To conclude, the team presented the results of the analysis of the rotating public parking for key stakeholders to obtain feedback and validate the proposal.

\subsection{Implementation Evaluation}

We evaluated the implementation of the A2BP method during the second cycle of DSR. The case studies at organisation A and $\mathrm{B}$ were conducted in a similar manner. We adopted the same data collection procedure consisting of observation, diary, and questionnaire in both case studies. At organisation B, analysts dedicated more time and effort to implement and evaluate our method. They had 18 meetings, totalising 42 hours to apply our method. One author observed all these meetings and produced 24 pages of observation notes, including general comments and difficulties faced by the analysts.

Analysts wrote a board diary reporting their experience during the use of the method. We asked them to describe the results, positive and negative views, difficulties, and suggestions. At the end of the case study, analysts answered a questionnaire to evaluate their perceived ease of use and utility of the method, suggestions, and criticisms. Examples of feedbacks included: "Clarify the sequence in which the techniques should be performed", "Reduce the impression that the A2BP method is complex and takes a long time to execute. Once I applied, I realised that it is useful but it was a bit difficult to understand at first", "The method has strong elements to stimulate innovation in processes, allowing to balance the use of explorative and exploitative thinking", "The method allowed us to identify novel improvement opportunities".

The case study demonstrated the applicability of the method and we obtained valuable feedback from practitioners to further refine it. The main drawback concerns the comprehensibility of ambidexterity concept and expertise to apply exploration techniques. Since it was the first time that analysts used these techniques, they had some initial difficulty. However, we believe that once they obtain more experience in ambidextrous analysis, they will be able to apply the exploration techniques more easily. In future versions of the method, we will try to provide better guidance on the use of exploration techniques and include more examples of techniques.

\section{Discussion}

\subsection{Contributions and Related Work}

Previous studies highlighted the growing importance of exploitative and explorative thinking in BPM [4, 44, 45, 18, 46, 15]. In particular, Rosemann [4] claims that ambidextrous BPM is a key area to further advance research and practice of BPM. Our paper aimed to address this research opportunity. Following a Design Science Research approach, we designed a conceptual model (scientific contribution) and a method (practical contribution) to support the ambidextrous analysis of business processes. In this paper, we report in details the second cycle of DSR as presented in Figure 2. During this study, we refined the method based on the reflections from the first cycle and designed the conceptual model. In particular, the conceptual model is grounded on concepts from a mapping study as well as empirical data obtained in cycle 1 of Design Science Research. Our conceptual model describes a shared language to communicate constructs between researchers. This is an original contribution to increase awareness and understanding of ambidextrous BPM domain.

We evaluated both artefacts with an expert opinion survey. The method was implemented by means of a case study at organisation B. In the case study, the analysis team applied our method to analyse the public rotating parking process. The team identified opportunities for improvement with a focus on operational efficiency, cost reduction, and automation, as well as, opportunities for innovation that create flexible and novel solutions using mobile technologies. 


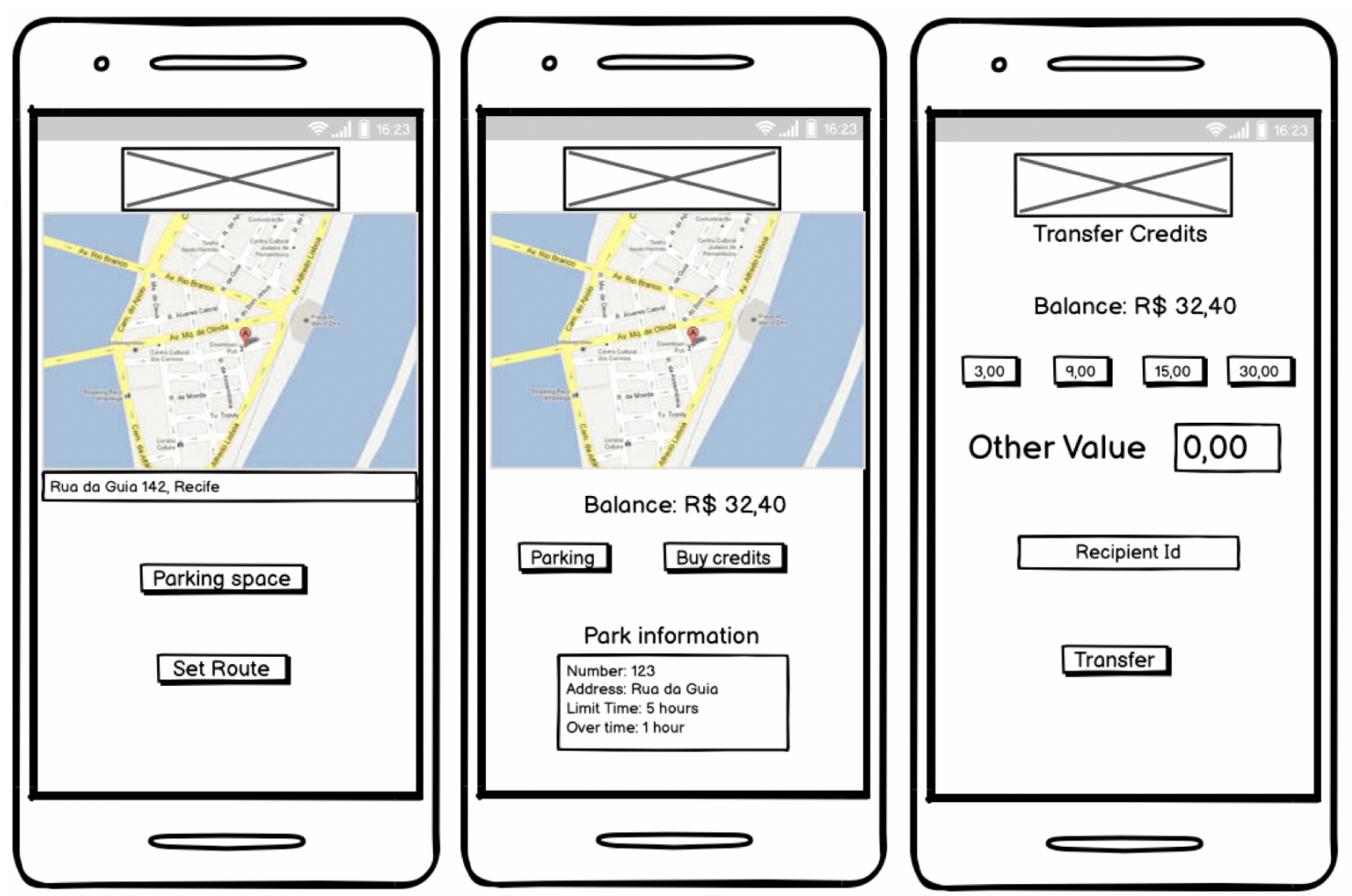

Figure 7. Prototype developed by the Organisation B

In sum, this paper sheds light on how to integrate exploitative and explorative thinking in business process analysis by proposing a novel method and conceptual model. Another contribution is the adoption of Design Science Research as an empirical method for BPM research. Here, we explained in details how the DSR lifecycle was conducted and which research methods were used in each phase. This detailed report may be useful for other BPM researchers willing to adopt Design Science Research.

Our findings suggest that using both exploitative and explorative techniques during the process analysis allows BPM teams to reason about the process in a holistic way. In doing so, organisations can achieve incremental improvements of their existing processes that enable them to operate more efficiently and deliver greater value to customers. Simultaneously, organisations can explore disruptive technologies and market trends that allow them to rethink their entire structure and create innovative products and services. We would like to emphasise that the decision to adopt specific explorative and/or exploitative technique depends on managerial and strategic decisions. For instance, the decisions might consist of either increasing efficiency of an existing process or exploring possible new value propositions. This balancing mindset is a key capability for ambidextrous organisations [4]. However, it is a challenging goal to achieve because exploitation and exploration are intrinsically inconsistent and contradictory [47]. Our study provides an initial attempt to reconcile these forces. Several recent studies have also contributed to the field of explorative BPM, ambidextrous BPM and are related to ours. Grisold et al. [15] defined explorative BPM and its characteristics in which compared to the traditional exploitative perspective, it is opportunity-driven and includes the creation of new processes offering new value propositions. Del Giudice et al. [46] investigated the impact of combining exploitative and explorative business process IT capabilities on business process performance by means of a quantitative survey study in the utility sector. Following a similar direction, Ferraris, Monge and Mueller [48], Xie, Link and Zhang [6] and Servegnini, Vieira and Cardoza [49] have also confirmed the relation between ambidextrous capabilities and business process performance. Miglietta et al. [50] explored the relationship between capital structure and BPM within ambidextrous firms.

Other authors investigated organisational aspects necessary to embrace an ambidextrous viewpoint. For instance, Lin and McDonough [8] analysed the importance of strategic leadership in creating an organisational culture aligned with ambidexterity. Dover and Dierk [51] analysed the roles of managers, entrepreneurs and leaders to foster ambidextrous capabilities in order to sustain future organisational success. Giacosa et al. [52] conducted a grounded theory study on family firms to understand their specific cultural and cognitive aspects, values and abilities to build an ambidextrous state in BPM initiatives. In summary, these studies explore ambidexterity from different perspectives.

In a different line, Cereja et al. [53] presented an empirical study at an insurance company that aligns the Design Thinking stages with the phases of BPM lifecycle. This study is 
closely related to ours. However, the authors do not propose a concrete approach, they simply report the experience of a firm. To the best of our knowledge, there is a lack in the literature of a systematic approach integrating ambidextrous thinking into the BPM lifecycle. It is important to highlight that both the A2BP model and method are not intended to evaluate the effects of the proposed improvements and/or innovations. Our paper differs and extends previous studies because we defined a conceptual model and designed a method with exploitative and explorative techniques integrated into the process analysis phase of BPM.

\subsection{Limitations and Future Research}

We followed a rigorous methodological approach to design and evaluate the proposed artefacts. Nevertheless, our study faces some limitations. As already discussed, we designed the method and conceptual model based on a mapping study. There is a risk that relevant papers may have been missed in the initial design of the method (i.e. cycle 1 of DSR). To address this problem, we complemented the mapping study in the second cycle of DSR.

A potential limitation of our study refers to the selection of organisation for the case study and experts who participated in the survey. Overall, we selected experts in BPM but some participants did not have previous experience in ambidexterity. Therefore, we may have some bias and inconsistency in their opinion. Similarly, organisation B has extensive experience in BPM projects. However, process analysts did not have much expertise in intuitive and creativity techniques. Therefore, we observed that analysts took more time to execute some activities of the method since it was the first time they applied such techniques. We believe that in future BPM projects, participants may perform the analysis more efficiently. Another limitation is that only 17 experts participated in the evaluation. Therefore, our results do not have statistical significance.

Due to time constraints, we were not able to verify if the improvement and innovation opportunities identified for the rotating public parking process were fully implemented by the organisation. This limitation gives room to further research. For instance, we could conduct two studies to compare the results of the process analysis with the use of our method and without it. Another direction for research is defining a set of competencies for analysts to successfully conduct ambidextrous BPM projects. In particular, we believe that expertise in design thinking is extremely valuable in this context. In future studies, we would like to implement the method at organisations from different domains and with BPM maturity levels to evaluate the suitability of our approach in different contexts.

We decided to focus specifically on the analysis phase of BPM because it is the moment when analysts critically assess the current problems and discuss possibilities to innovate the business process. It was a rational decision to narrow the problem space. Clearly, there is a promising avenue for future research to investigate how ambidextrous thinking can be intertwined with the whole BPM lifecycle. As a further refinement of our method, we aim to expand it to cover all phases of BPM.

\section{Author contributions}

The work presented here was carried out in collaboration between both authors. Both authors have read and agreed to the published version of the manuscript.

\section{References}

[1] DUMAS, M. et al. Fundamentals of Business Process Management. 2013. ed. Berlin: Springer, 2013.

[2] SCHMIEDEL, T.; BROCKE, J. v.; RECKER, J. Culture in Business Process Management: How Cultural Values Determine BPM Success. In: ROSEMANN, M AND VOM BROCKE, J. Handbook on Business Process Management 2: Strategic alignment, governance, people and culture [international handbooks on information systems]. 2. ed. Berlin: Springer, 2015. p. 649-664.

[3] VAN LOOY, A. On the synergies between business process management and digital innovation. In: BUSINESS PROCESS MANAGEMENT: INTERNATIONAL CONFERENCE, BPM, 16., 2018, Sydney. Proceedings of the [...]. Sydney: Springer Nature, 2018. v. 11080, p. 359-375. Disponível em: 〈http://dx.doi.org/10.1007/ 978-3-319-98648-7_21).

[4] ROSEMANN, M. Proposals for Future BPM Research Directions. In: ASIA PACIFIC BUSINESS PROCESS MANAGEMENT CONFERENCE AP-BPM, 2., 2014, Brisbane. Proceedings of the [...]. Cham: Springer, 2014. p. 1-15.

[5] HECKMANN, C. The Impact of Business Process IT Ambidexterity on Business Process Performance. In: ECIS - EUROPEAN CONFERENCE ON INFORMATION SYSTEMS, 23., 2015, Münster. Proceedings of the [...]. Atlanta: Jörg Becker, 2015. p. paper 23.

[6] XIE, R.; LING, H.; ZHANG, C. Effect of business process management on firm performance: An ambidexterity perspective. In: BMEI - INTERNATIONAL CONFERENCE ON BUSINESS MANAGEMENT AND ELECTRONIC INFORMATION, 2011, Guangzhou. Proceedings of the [...]. Guangzhou: IEEE, 2011. v. 3, p. 341-345.

[7] BROCKE, J. V.; ZELT, S.; SCHMIEDEL, T. On the role of context in business process management. International Journal of Information Management, [S.1.], v. 36, n. 3, p. 486-495, junho de 2016.

[8] LIN, H. E.; MCDONOUGH, E. F. Investigating the role of leadership and organizational culture in fostering innovation ambidexterity. IEEE Transactions on Engineering Management, [S.1.], v. 58, n. 3, p. 497-509, agosto de 2011. 
[9] LINDSKOG, C. Exploitation and Exploration in Business Process Management - An exploratory paper. In: INTERNATIONAL CONFERENCE ON PERSPECTIVES IN BUSINESS INFORMATICS RESEARCH (BIR), 17., 2018, Stockholm. Proceedings of the [...]. Stockholm: CEUR-WS, 2018. p. 405-414.

[10] ELSBACH, K. D.; STIGLIANI, I. Design Thinking and Organizational Culture: A Review and Framework for Future Research. Journal of Management, [S.1.], v. 44, n. 6, p. 2274 2306, julho de 2018.

[11] O'REILLY, C. A.; TUSHMAN, M. L. The Ambidextrous Organization. Harvard business review, Brighton, v. 82, n. 4, p. 74-81, 140, maio de 2013.

[12] HE, Z.-L.; WONG, P.-K. Exploration vs. Exploitation: An Empirical Test of the Ambidexterity Hypothesis. Organization Science, Catonsville, v. 15, n. 4, p. 481-494, agosto de 2004.

[13] BAUER, M.; LEKER, J. Exploration and exploitation in product and process innovation in the chemical industry. R\&D Management, v. 43, n. 3, p. 196-212, 2013.

[14] CHEN, E.; KATILA, R. Rival interpretations of balancing exploration and exploitation: Simultaneous or sequential? In: SHANE, S. (ed.). Handbook of Technology and Innovation Management. Chichester: Wiley, 2008. v. 1, p. 197-214. [15] GRISOLD, T. et al. Exploring Explorative BPM: Setting the Ground for Future Research. In: BUSINESS PROCESS MANAGEMENT FORUM: BPM FORUM, 17., 2019, Vienna. Proceedings of the [...]. Cham, 2019. p. 23-31.

[16] BENEDICT, T. et al. BPM CBOK Version 3.0: Guide to the Business Process Management Common Body of Knowledge. 3. ed. [S.1.]: CreateSpace / ABPMP - Association of Business Process Management Professionals, 2013. E-book. Disponível em: 〈https://www.bibsonomy.org/bibtex/ 2093e28d46d9735a7678f818a075be33b/flint63〉.

[17] JESTON, J.; NELIS, J. Business Process Management Practical Guidelines to Successful Implementations. 1. ed. Oxford: Butterworth-Heinemann, 2015.

[18] KOHLBORN, T. et al. Interview with Michael Rosemann on ambidextrous business process management. Business Process Management Journal, Bingley, v. 20, n. 4, p. 634-638, julho de 2014.

[19] VERGIDIS, K.; TIWARI, A.; MAIEED, B. Business Process Analysis and Optimization: Beyond Reengineering. IEEE Transactions on Systems, Man and Cybernetics Part C: Applications and Reviews, New York, v. 38, n. 1, p. 69-82, fevereiro de 2008.

[20] MALINOVA, M.; HRIBAR, B.; JAN, M. A framework for assessing BPM success. In: ECIS - EUROPEAN CONFERENCE ON INFORMATION SYSTEMS, 22., 2014, Tel Aviv. Proceedings of the [...]. Tel Aviv: Association for Information Systems, 2014. p. seção 6, artigo 5.

[21] IIBA. A Guide to the Business Analysis Body of Knowledge (BABOK Guide). 2. ed. Toronto: International Institute of Business Analysis, 2009.
[22] BROWN, T.; WYATT, J. Design Thinking for Social Innovation By Stanford Social Innovation Review. Stanford Social Innovation Review, Washington, v. 8, n. 1, p. 30-35, julho de 2010.

[23] RICHARDSON, C. et al. Design For Disruption: Take An Outside-In Approach To BPM. Cambridge: Forrester Research, 2013.

[24] MARTIN, R. Design of Business: Why Design Thinking is the Next Competitive Advantage. 2. ed. Boston: Harvard Business Review, 2009.

[25] BROWN, T. Change by design: how design thinking transforms organizations and inspires innovation. 1. ed. New York: Harper Business, 2009.

[26] CHASANIDOU, D.; GASPARINI, A. A.; LEE, E. Design Thinking Methods and Tools for Innovation. In: DESIGN, USER EXPERIENCE, AND USABILITY: DESIGN DISCOURSE INTERNATIONAL CONFERENCE, DUXU, 4., 2015, Los Angeles. Proceedings of the [...]. Cham: Springer International Publishing, 2015. p. 12-23.

[27] SANTOS, H.; ALVES, C. Exploring the Ambidextrous Analysis of Business Processes: A Design Science Research. In: HAMMOUDI, S. et al. (Ed.). Enterprise Information Systems - ICEIS. Cham: Springer International Publishing, 2018. p. 543-566.

[28] WIERINGA, R. J. What Is Design Science? In: WIERINGA, ROEL J. Design Science Methodology for Information Systems and Software Engineering. Berlin: Springer, 2014. p. 3-11.

[29] SJOBERG, D. I. et al. Building theories in software engineering. In: SHULL, FORREST AND SINGER, JANICE AND SJØBERG, DAG I.K. Guide to Advanced Empirical Software Engineering. Berlin: Springer, 2008. p. 312-336.

[30] O'REILLY, C. A.; TUSHMAN, M. L. Organizational ambidexterity: Past, present, and future. Academy of Management Perspectives, New York, v. 27, n. 4, p. 324-338, novembro de 2013.

[31] BANDARA, W.; GABLE, G. G.; ROSEMANN, M. Factors and measures of business process modelling: Model building through a multiple case study. European Journal of Information Systems, Abingdon, v. 14, n. 4, p. 347-360, dezembro de 2005.

[32] BURLTON, R. T. BPM Critical Success Factors: Lessons Learned from Successful BPM Organizations. Business Rules Journal, [S.1.], v. 12, n. 10, p. 1-6, 2011. Disponível em: 〈http://www.brcommunity.com/a2011/b619. html $\rangle$.

[33] JURISCH, M. C. et al. Which capabilities matter for successful business process change? Business Process Management Journal, Bingley, v. 20, n. 1, p. 47-67, janeiro de 2014. 
[34] MORAIS, R. M. de et al. An analysis of BPM lifecycles: From a literature review to a framework proposal. Business Process Management Journal, Bingley, v. 20, n. 3, p. 412432, maio de 2014.

[35] NIEHAVES, B.; HENSER, J. Business process management beyond boundaries? - A multiple case study exploration of obstacles to collaborative BPM. In: ANNUAL HAWAII INTERNATIONAL CONFERENCE ON SYSTEM SCIENCES, 44., 2011, Kauai. Proceedings of the [...]. Kauai: IEEE Computer Society, 2011. p. 1-13.

[36] PAIM, R. Tasks for Process Management. Tese (Doutorado em Engenharia de Produção) — Instituto Alberto Luiz Coimbra de Pós-Graduação e Pesquisa em Engenharia (COPPE) - UFRJ, Rio de Janeiro, 2007.

[37] ROSEMANN, M.; VOM BROCKE, J. The six core elements of business process management. In: ROSEMANN, M.; VOM BROCKE, J. (Ed.). Handbook on Business Process Management 1: Introduction, methods, and information systems [international handbooks on information systems]. Berlin: Springer, 2015. p. 105-122.

[38] TRKMAN, P. The critical success factors of business process management. International Journal of Information Management, [S.1.], v. 30, n. 2, p. 125-134, abril de 2010.

[39] OSTERWALDER, A. The business model ontology a proposition in a design science approach. Tese (Doutorado em Gerenciamento de TI) - Université de Lausanne, Faculté des hautes études commerciales, Lausana, 2004.

[40] MARKIDES, C. Six principles of breakthrough strategy. Business Strategy Review, London, v. 10, n. 2, p. 1-10, 1999.

[41] TURBER, S.; SMIELA, C. A business model type for the internet of things. In: ECIS - EUROPEAN CONFERENCE ON INFORMATION SYSTEMS, 22., 2014, Tel Aviv. Proceedings of the [...]. Oxford: Butterworth-Heinemann, 2014.

[42] LOCKWOOD, T. Design Thinking: Integrating Innovation, Customer Experience, and Brand Value. 1. ed. New York: Allworth Press, 2009.

[43] RECKER, J.; ROSEMANN, M. Being innovative without being creative. Australia: Information Systems School, Queensland University of Technology, 2014. (QUT Innovation Briefs). E-book. Disponível em: 〈https://eprints.qut.edu. $\mathrm{au} / 75985 /\rangle$.

[44] HELBIN, T.; VAN LOOY, A. Business process ambidexterity and its impact on business-it alignment: A systematic literature review. In: INTERNATIONAL CONFERENCE ON
RESEARCH CHALLENGES IN INFORMATION SCIENCE (RCIS), 13., 2019. Proceedings of the [...]. Brussels: IEEE, 2019. p. 1-12.

[45] HELBIN, T. Investigating How Business Process Ambidexterity Facilitates Business-IT Alignment in Public Sector Organizations. In: INTERNATIONAL CONFERENCE ON RESEARCH CHALLENGES IN INFORMATION SCIENCE (RCIS), 13., 2019. Proceedings of the [...]. Brussels: IEEE, 2019. p. $1-5$.

[46] DEL GIUDICE, M. et al. Emerging perspectives on business process management (BPM): IT-based processes and ambidextrous organizations, theory and practice. Business Process Management Journal, Bingley, v. 24, p. 1070-1076, setembro de 2018.

[47] MARCH, J. G. Exploration and Exploitation in Organizational Learning. Organization Science, Catonsville, v. 2, n. 1, p. 71-87, 1991.

[48] FERRARIS, A.; MONGE, F.; MUELLER, J. Ambidextrous IT capabilities and business process performance: an empirical analysis. Business Process Management Journal, Bingley, v. 24, n. 5, p. 1077-1090, junho de 2018.

[49] SEVERGNINI, E.; VIEIRA, V. A.; CARDOZA GALDAMEZ, E. V. The indirect effects of performance measurement system and organizational ambidexterity on performance. Business Process Management Journal, Bingley, v. 24, n. 5, p. 1176-1199, setembro de 2018.

[50] MIGLIETTA, N. et al. Capital structure and business process management: evidence from ambidextrous organizations. Business Process Management Journal, Bingley, v. 24, n. 5, p. 1255-1270, setembro de 2018.

[51] DOVER, P. A.; DIERK, U. The ambidextrous organization: Integrating managers, entrepreneurs and leaders. Journal of Business Strategy, Karachi, v. 31, n. 5, p. 49-58, setembro de 2010.

[52] GIACOSA, E.; MAZZOLENI, A.; USAI, A. Business Process Management (BPM): How complementary BPM capabilities can build an ambidextrous state in business process activities of family firms. Business Process Management Journal, Bingley, v. 24, n. 5, p. 1145-1162, setembro de 2018.

[53] CEREJA, J. R. et al. Application of the Design Thinking Approach to Process Redesign at an Insurance Company in Brazil. In: BROCKE, J. vom; MENDLING, J. (Ed.). Business Process Management Cases: Digital Innovation and Business Transformation in Practice. 1. ed. Cham: Springer International Publishing, 2018. p. 201-213. 